\title{
Global Free Trade is in the Core of a
}

\author{
Customs Union Game*
}

\author{
Hideo Konishi ${ }^{\dagger}$ Carsten Kowalczyk Tomas Sjöström $^{\ddagger}$
}

First Version: May 2003

This Version: June 2008

*We thank an anonymous referee for helpful comments. Konishi thanks KIER in Kyoto University for their hospitality and financial support. Kowalczyk acknowledges with thanks support from a sabbatical leave at Tufts. The paper is part of the Globalization Project at the University of Aarhus.

${ }^{\dagger}$ Department of Economics, Boston College, 140 Commonwealth Ave., Chestnut Hill, MA 02467; (Phone) 617-969-2959; (Email): hideo.konishi@bc.edu

†The Fletcher School, Tufts University, MA 02155; (Phone): 617-627-5603; (Email): carsten.kowalczyk@tufts.edu

$\S$ Department of Economics, Rutgers University, New Brunswick, NJ 08901; (Phone): 732-932-8383; (Email): tsjostrom@economics.rutgers.edu 


\begin{abstract}
This paper shows nonemptiness of the core of a customs union game with a status quo equilibrium with tariffs by employing an appropriate notion of the core as in Kowalczyk and Sjöström (1994, Economica). Specifically, we find that if customs unions may have no effects on non-member countries as in Ohyama (1972, Keio Economic Studies) and Kemp and Wan (1976, Journal of International Economics) then a subset of countries forming such a customs union does not block global free trade when accompanied by so-called Grinols transfers (Grinols, 1981, Journal of International Economics).
\end{abstract}

\title{
1 Introduction
}

GATT Article XXIV defines a customs union as an agreement between its members to eliminate barriers on substantially all trade while setting common tariffs on external trade with non-members where these tariffs on average not be raised. What are the effects on the welfare of countries and on the world from custom unions? And what effects do customs unions have on global 
free trade - do they hinder or support a world-wide agreement to eliminate all trade barriers?

Regarding the first question, Viner (1950) showed that a customs union may lower welfare of the participants and even the world. However, Ohyama (1972) and Kemp and Wan (1976) showed that if customs unions are required to set their compensating external tariffs, i.e., if the member countries must adjust their tariffs to leave their trade with non-members constant, then for any such customs union there are intra-union income transfers such that no union member loses. ${ }^{1}$ It is a corollary that global free trade can be reached through expanding Ohyama-Kemp-Wan customs unions such that no country loses during the process of expansion.

With respect to the second question, Riezman (1985), Kennan and Riezman (1990), and Bond and Syropoulos (1996) demonstrate, in three-country environments, how the ability to form customs unions, through the effect on the custom union members' optimal tariffs on a non-member, in some circumstances can be used by member countries to upset global free trade and in other circumstances, by the threat of imposing more severe retaliation, can discourage a large non-member country from breaking away from free

\footnotetext{
${ }^{1}$ Kemp and Shimomura (2001) show that this proposition also holds if non-member countries adjust their tariffs to their optimal levels after the formation of a customs union.
} 
trade.

Using a general equilibrium existence proof, we show in this paper that global free trade with income transfers is in the core of a customs union game if customs unions are required to be of the Ohyama-Kemp-Wan type. ${ }^{2}$ We show, in particular, that transfers that would enable each country to consume its initial consumption bundle supports global free trade as an allocation in the above notion of the core. ${ }^{3}$ In our companion paper, Konishi, Kowalczyk, and Sjöström (2003), we discuss how these transfers amount to offsetting any terms-of-trade effects associated with moving to global free trade, and we offer an alternative proof of our result by applying the welfare calculus of tariffs.

We define the world economy in section 2, and we introduce tariffs and state the Ohyama-Kemp-Wan Theorem in section 3. We prove our main result in section 4 . Section 5 concludes.

\footnotetext{
${ }^{2}$ This notion of the core was introduced by Kowalczyk and Sjöström (1994).

${ }^{3}$ Drawing on work by Grandmont and McFadden (1972), Grinols (1981) proposed these transfers between members of Ohyama-Kemp-Wan customs unions.
} 


\section{The Economy}

The economy is identical to Kemp and Wan (op. cit.). Kemp and Wan offered a verbal, yet quite precise, description of the model (they only omitted local nonsatiation). We will present the model and the proof more formally. The model can be generalized more in known ways in the theory of general equilibrium.

The finite set of countries is denoted by $N=\{1,2, \ldots, n\}$. There are $K$ goods in the economy. For each country $i \in N$, (i) the consumption set $X^{i}$ is a subset of a $K$-dimensional Euclidean space $\mathbb{R}^{K}$ that is closed, convex and bounded below, (ii) the endowment $\omega^{i} \in \mathbb{R}^{K}$, (iii) the production set $Y^{i} \subseteq \mathbb{R}^{K}$ is closed and convex, and $0 \in Y^{i}, \mathbb{R}_{-}^{K} \subseteq Y^{i}$, and $Y^{i} \cap \mathbb{R}_{++}^{K}=\emptyset$, and (iv) preferences over $X^{i}$ can be represented by a continuous quasiconcave utility function $u^{i}: X^{i} \rightarrow \mathbb{R}$ such that for any $x \in X^{i}$, any $\epsilon>0$, there exists $x^{\prime} \in X^{i}$ with $\left\|x^{\prime}-x\right\|<\epsilon$ and $u^{i}\left(x^{\prime}\right)>u^{i}(x)$ (local nonsatiation). An economy is a list $\left(N,\left(X^{i}, Y^{i}, \omega^{i}, u^{i}\right)_{i \in N}\right)$.

Under the listed assumptions, we can confine our attention to nonnegative prices for each commodity. Let $\Delta=\left\{p \in \mathbb{R}_{+}^{K}: \sum_{k=1}^{K} p_{k}=1\right\}$ be a price simplex. A (free-trade) market equilibrium is a list $\left(p^{*},\left(x^{i *}, y^{i *}\right)_{i \in N}\right) \in \Delta \times$ $\left(\prod_{i \in N} X^{i} \times Y^{i}\right)$ such that (a) $\sum_{i \in N} x^{i *}=\sum_{i \in N} \omega^{i}+\sum_{i \in N} y^{i *}$, and for each 
$i \in N$, we have (b) $x^{i *}=\arg \max u^{i}\left(x^{i \prime}\right)$ over the set $\left\{x^{i \prime} \in X^{i}: p^{i} x^{i \prime} \leq\right.$ $p^{i} \omega^{i}+p^{i} y^{i}$, and (c) $y^{i *}=\arg \max p^{i} y^{i \prime}$ over the set $y^{i \prime} \in Y^{i}$.

\section{Tariff Equilibrium and the Ohyama-Kemp-}

\section{Wan Theorem}

Suppose that there are initially tariffs (and subsidies) in the world economy. Let $p^{e} \in \Delta$ be the world price vector, and $p^{i} \in \Delta$ be country $i$ 's domestic price vector. Country $i$ 's tariff vector $t^{i} \in \mathbb{R}^{K}$ is arbitrarily given and satisfies $t^{i}=$ $p^{i}-p^{e}{ }^{4}$ Let $m^{i}=x^{i}-\omega^{i}-y^{i}$ be country $i$ 's import vector. A tariff equilibrium with a tariff vector $t=\left(t^{i}\right)_{i \in N}, E(t)$, is a list $\left(p^{e},\left(p^{i}, x^{i}, y^{i}, m^{i}\right)_{i \in N}\right) \in \Delta \times$ $\left(\prod_{i \in N} \mathbb{R}_{+}^{K} \times X^{i} \times Y^{i} \times \mathbb{R}^{K}\right)$ such that (a) $\sum_{i \in N} x^{i}=\sum_{i \in N} \omega^{i}+\sum_{i \in N} y^{i}$, and for each $i \in N$, we have (b) $x^{i}=\arg \max u^{i}\left(x^{i \prime}\right)$ over the set $\left\{x^{i \prime} \in X^{i}\right.$ : $\left.p^{i} x^{i \prime} \leq p^{i} \omega^{i}+p y^{i}+t^{i} m^{i}\right\},(\mathrm{c}) y^{i}=\arg \max p^{i} y^{i \prime}$ over the set $y^{i \prime} \in Y^{i}$, (d) $p^{i}=p^{e}+t^{i}$, (e) $m^{i}=x^{i}-\omega^{i}-y^{i}$, and (f) $p^{e} x^{i}=p^{e} \omega^{i}+p^{e} y^{i}$.

Now, we consider a customs union formed by a coalition $S \subseteq N$. A

\footnotetext{
${ }^{4}$ For notational simplicity, we assume specific tariffs which implies that $p^{e}+t^{i}>0$ to ensure positive domestic prices. We use tariff equilibrium for the purpose of describing the initial economy only, so we can assume the existence of an equilibrium with positive domestic prices. If instead rates had been assumed to be ad valorem, where $p^{i}=p^{e}\left(1+\tau^{i}\right)$, then as long as $\tau^{i}>-1\left(\tau^{i}=-1\right.$ means a $100 \%$ import subsidy), the existence of tariff equilibrium is guaranteed.
} 
suballocation for coalition $S$ relative to $E(t)$ is $\left(\tilde{x}^{i}, \tilde{y}^{i}\right)_{i \in S} \in\left(\prod_{i \in S} X^{i} \times Y^{i}\right)$ such that (a) $\sum_{i \in S} \tilde{x}^{i}+\sum_{i \in N \backslash S} x^{i}=\sum_{i \in N} \omega^{i}+\sum_{i \in S} \tilde{y}^{i}+\sum_{i \in N \backslash S} y^{i}$, and (b) for each $i \in S, x^{i} \in X^{i}$ and $y^{i} \in Y^{i}$. A market equilibrium for coalition $S$ relative to $E(t)$ with internal transfers $T^{S}$ is a list $\left(\left(\bar{x}^{i}, \bar{y}^{i}\right)_{i \in S}, \bar{p}, T^{S}\right) \in$ $\left(\prod_{i \in S} X^{i} \times Y^{i}\right) \times \mathbb{R}_{++}^{K} \times \mathbb{R}^{S}$ such that (1) $\left(\bar{x}^{i}, \bar{y}^{i}\right)_{i \in S}$ is a suballocation for coalition $S$ relative to $E(t),(2) \bar{p} \in \Delta$ is a common internal price vector, (3) for each $i \in S, \bar{x}^{i}=\arg \max u^{i}\left(x^{i \prime}\right)$ over the set $\left\{x^{i \prime} \in X^{i}: \bar{p} x^{i \prime} \leq\right.$ $\left.\bar{p} \omega^{i}+\bar{p} \bar{y}^{i}+T^{i}\right\}$, (4) for each $i \in S, y^{i}=\arg \max \bar{p} y$ over the set $y \in Y^{i}$, and (5) $T^{S}=\left(T^{i}\right)_{i \in S} \in \mathbb{R}^{S}$ with $\sum_{i \in S} T^{i}=\left(p^{\prime}-p^{e}\right) \sum_{i \in S} m^{i}$.

Note that the requirement in (5) says that the sum of the transfers are equal to the sum of tariff revenues by the members as $\left(p^{\prime}-p^{e}\right)$ denotes a common tariff vector for coalition $S$. Thus, $T^{S}$ is internal transfers within coalition $S$. By assigning the original allocation in $E(t)$ to $N \backslash S$, a coalition $S$ can achieve suballocation $\left(\bar{x}^{i}, \bar{y}^{i}\right)_{i \in S}$ as a market equilibrium allocation by removing tariffs within $S$, with a common external tariff vector $\left(\bar{p}-p^{e}\right)$ and with internal transfers $T^{S}$. A market equilibrium for grand coalition $N$ relative to $E(t)$ with internal transfers is somewhat special, since $E(t)$ does not matter for the grand coalition, and the transfers $T^{N}$ need to satisfy $\sum_{i \in N} T^{i}=0$, where world-wide materials balance implies $\sum_{i \in N} m^{i}=0$. 
There are no longer tariffs in the economy. We call this equilibrium for the grand coalition $\left(\left(\bar{x}^{i}, \bar{y}^{i}\right)_{i \in N}, \bar{p}, T^{N}\right)$ a free trade equilibrium with transfers $T^{N}$.

The Ohyama-Kemp-Wan theorem can be stated formally in the following manner: For any market equilibrium with tariff vector $t, E(t)$, for any nonempty coalition $S \subseteq N$, there exists a market equilibrium for $S$ relative to $E(t)$ with $T^{S},\left(\left(\bar{x}^{i}, \bar{y}^{i}\right)_{i \in S}, \bar{p}, T^{S}\right)$ such that $u^{i}\left(\bar{x}^{i}\right) \geq u^{i}\left(x^{i}\right)$ for each $i \in S$. Thus, by assigning the same allocation to outsiders, $\left(p^{i}, x^{i}, y^{i}\right)_{i \in N \backslash S}$, members of a customs union $S$ can achieve higher welfare in a Pareto fashion by setting the same tariff rate $\bar{t}=\bar{p}-p^{e}$ with an appropriate transfer vector $T^{S}$ within S.

Kemp and Wan proved the theorem by using the second welfare theorem.

\section{Nonemptiness of the Core}

In a custom union formation problem, there are in general externalities across customs unions, since there is usually trade between nations that are members of different customs unions (unless tariff rates are prohibitively high). Thus, the usual definition of the core in characteristic function form games does not work well (see, for example, Riezman (op. cit.)). We de- 
fine our notion of the core following Kowalczyk and Sjöström (1994). An allocation $\left(\check{x}^{i}, \breve{y}^{i}\right)_{i \in N}$ is a core allocation relative to $E(t)$, if for any coalition $S \subseteq N$, there is no suballocation for $S$ relative to $E(t),\left(\tilde{x}^{i}, \tilde{y}^{i}\right)_{i \in S}$, such that $u^{i}\left(\tilde{x}^{i}\right) \geq u^{i}\left(\check{x}^{i}\right)$ for all $i \in S$ and $u^{i^{\prime}}\left(\tilde{x}^{i^{\prime}}\right)>u^{i^{\prime}}\left(\check{x}^{i^{\prime}}\right)$ for some $i^{\prime} \in S$. The core relative to $E(t)$ is a collection of core allocations relative to $E(t)$. We prove nonemptiness of the core by constructing an economy with transfers as defined in Grinols (1981). Fix $E(t)=\left(p^{e},\left(p^{i}, x^{i}, y^{i}\right)_{i \in N}\right)$, and consider a ficticious economy with endowment transfers $\left(N,\left(X^{i}, Y^{i}, \bar{\omega}^{i}, u^{i}\right)_{i \in N}\right)$ where $\bar{\omega}^{i}=\omega^{i}+m^{i}$. We consider in particular income transfers that enable each country to consume its pre-liberalization consumption vector, implying that country $i$ receives a transfer $m^{i}$, or when valued at post-change prices, $\bar{T}^{i}=p^{*} m^{i}$, where $p^{*}$ is the post-liberalization equilibrium price vector. We denote these as Grinols transfers. ${ }^{5}$ Our main result is as follows:

Theorem. The core relative to $E(t)$ is nonempty if $x^{i} \in \operatorname{int}\left(X^{i}\right)$ for each $i \in N .^{6}$ In particular, there exists a free trade equilibrium with Grinols transfers, and it is in the core.

\footnotetext{
${ }^{5}$ Kowalczyk and Sjöström (2000).

${ }^{6}$ Assumption $x^{i} \in \operatorname{int}\left(X^{i}\right)$ for all $i \in N$ simply says that each country $i$ 's tariff equilibrium consumption vector is not on the border of its consumption set. In the international trade context, it is an innocuous assumption, and Kemp and Wan (1976) also assume it.
} 
The following lemma proves the existence of free trade equilibrium with Grinols transfer in this economy:

Lemma. There exists a market equilibrium $\left(p^{*},\left(x^{i *}, y^{i *}\right)_{i \in N}\right)$ in an economy $\left(N,\left(X^{i}, Y^{i}, \bar{\omega}^{i}, u^{i}\right)_{i \in N}\right)$ generated from $E(t)$ if $x^{i} \in \operatorname{int}\left(X^{i}\right)$ for each $i \in N$. Moreover, $\left(p^{*},\left(x^{i *}, y^{i *}\right)_{i \in N}, \bar{T}^{N}\right)$ is a market equilibrium with transfers $\bar{T}^{N}$, where $\bar{T}^{N}$ are the Grinols transfers.

Proof of Lemma. Since $X^{i}$ s are bounded below, and $Y^{i}$ s are convex and satisfy $Y^{i} \cap \mathbb{R}_{++}^{K}=\emptyset$, we can use standard arguments of truncating $X^{i}$ s and $Y^{i}$ S. Let $\tilde{X}^{i}$ S and $\tilde{Y}^{i}$ s be compact and convex truncated sets of $X^{i}$ s and $Y^{i} \mathrm{~S}$ that contain all feasible allocations in their interior. Note that $x^{i} \in\left\{\bar{\omega}^{i}\right\}+\tilde{Y}^{i}$; thus $\left\{\bar{\omega}^{i}\right\}+\tilde{Y}^{i} \cap \operatorname{int}\left(\tilde{X}^{i}\right) \neq \emptyset$. Let $B^{i}: \Delta \rightarrow \tilde{X}^{i}$ such that $B^{i}(p)=\left\{x^{i \prime} \in \tilde{X}^{i}\right.$ : $\left.p x^{i \prime} \leq p \bar{\omega}^{i}+\max _{y^{i \prime} \in Y^{i}} p y^{i \prime}\right\}$. Since $\left\{\bar{\omega}^{i}\right\}+\tilde{Y}^{i} \cap i n t\left(\tilde{X}^{i}\right) \neq \emptyset, B^{i}$ is continuous and nonempty-valued (see McKenzie, 1959). ${ }^{7}$ Let $\phi^{i}: \Delta \rightarrow \tilde{X}^{i}$ such that $\phi^{i}(p)=\left\{x^{i \prime} \in \tilde{X}^{i}: u^{i}\left(x^{i \prime}\right) \geq u^{i}\left(x^{i \prime \prime}\right)\right.$ for any $\left.x^{i \prime \prime} \in B^{i}(p)\right\}$. Let $\eta^{i}: \Delta \rightarrow \tilde{Y}^{i}$ be such that $\eta^{i}(p)=\arg \max _{y^{i \prime} \in \hat{Y}^{i}} p y^{i \prime}$. These are nonempty-valued and upper hemi-continuous by Weierstrass's and Berge's theorems, respectively. They are also convex-valued by quasiconcavity of $u^{i}$ and convexity of $Y^{i}$. Thus,

\footnotetext{
${ }^{7}$ For our economy, we cannot apply a standard assumption $\bar{\omega}^{i} \in \operatorname{int}\left(X^{i}\right)$ in Debreu (1959) since $\bar{\omega}^{i}=\omega^{i}+m^{i}$. We need to use a technique developed in McKenzie (op. cit.).
} 
a standard use of the Kakutani fixed point theorem and the Gale-Nikaido lemma together with the truncation argument (see Debreu, 1959) shows the existence of equilibrium in the fictitious economy $\left(p^{*},\left(x^{i *}, y^{i *}\right)_{i \in N}\right)$.

We can rewrite country $i$ 's budget constraint in the following way:

$$
\begin{aligned}
p^{*} x^{i *} & =p^{*} \bar{\omega}^{i}+p^{*} y^{i *} \\
& =p^{*}\left(\omega^{i}+m^{i}\right)+p^{*} y^{i *} \\
& =p^{*} \omega^{i}+p^{*} m^{i}+p^{*} y^{i *} \\
& =p^{*} \omega^{i}+p^{*} y^{i *}+\bar{T}^{i} .
\end{aligned}
$$

Since $\sum_{i \in N} m^{i}=0, \sum_{i \in N} \bar{T}^{i}=0$ follows, too. Hence, $\left(p^{*},\left(x^{i *}, y^{i *}\right)_{i \in N}, \bar{T}^{N}\right)$ is a market equilibrium with the Grinols transfers $\bar{T}^{N} . \square$

Proof of Theorem. Let $\left(p^{*},\left(x^{i *}, y^{i *}\right)_{i \in N}\right)$ be a market equilibrium in Lemma. We show that $\left(x^{i *}, y^{i *}\right)_{i \in N}$ is in the core relative to $E(t)$ of the original economy. Suppose not. Then, there exists a coalition $S$ and a suballocation $\left(\tilde{x}^{i}, \tilde{y}^{i}\right)_{i \in S}$ such that $u^{i}\left(\tilde{x}^{i}\right)>u^{i}\left(x^{i *}\right)$ for each $i \in S$. This implies that $p^{*} \tilde{x}^{i}>p^{*} \bar{\omega}^{i}+p^{*} \tilde{y}^{i}$ for each $i \in S$. Summing them up, we obtain $p^{*} \sum_{i \in S} \tilde{x}^{i}>p^{*} \sum_{i \in S} \bar{\omega}^{i}+p^{*} \sum_{i \in S} \tilde{y}^{i}$. However, by the definition of a subal- 
location, we have

$$
\sum_{i \in S} \tilde{x}^{i}+\sum_{i \in N \backslash S} x^{i}=\sum_{i \in N} \omega^{i}+\sum_{i \in S} \tilde{y}^{i}+\sum_{i \in N \backslash S} y^{i}
$$

or

$$
\begin{aligned}
\sum_{i \in S} \tilde{x}^{i} & =\sum_{i \in S} \omega^{i}+\sum_{i \in S} \tilde{y}^{i}-\left(\sum_{i \in N \backslash S} x^{i}-\sum_{i \in N \backslash S} \omega^{i}-\sum_{i \in N \backslash S} y^{i}\right) \\
& =\sum_{i \in S} \omega^{i}+\sum_{i \in S} \tilde{y}^{i}-\left(\sum_{i \in N \backslash S} m^{i}\right) \\
& =\sum_{i \in S} \omega^{i}+\sum_{i \in S} \tilde{y}^{i}+\left(\sum_{i \in S} m^{i}\right) \\
& =\sum_{i \in S} \bar{\omega}^{i}+\sum_{i \in S} \tilde{y}^{i} .
\end{aligned}
$$

We note that $\sum_{i \in N} m^{i}=\sum_{i \in N} x^{i}-\sum_{i \in N} \omega^{i}-\sum_{i \in N} y^{i}=0$. Thus, for any $p^{*} \in \Delta$, we must have $p^{*} \sum_{i \in S} \tilde{x}^{i}=p^{*} \sum_{i \in S} \bar{\omega}^{i}+p^{*} \sum_{i \in S} \tilde{y}^{i}$. This is a contradiction. Hence, the core relative to $E(t)$ is nonempty. $\square$

The above result extends to subeconomies. Now, consider a fictitious subeconomy with endowment transfers $\left(S,\left(X^{i}, Y^{i}, \bar{\omega}^{i}, u^{i}\right)_{i \in S}\right)$ for coalition $S$ such that $\bar{\omega}^{i}=\omega^{i}+m^{i}$ where $m^{i}=x^{i}-\omega^{i}-y^{i}$. A market equilibrium in such a subeconomy with Grinols transfers can be supported by a market 
equilibrium for $S$ relative to $E(t)$ with an internal transfer vector $\bar{T}^{S}=$ $\left(\bar{T}^{i}\right)_{i \in S}=\left(p_{S}^{*} m^{i}\right)_{i \in S}$, where $p_{S}^{*}$ is the common market price vector within $S$. The sum of transfers is equivalent to the collective tariff revenues within $S$ from the rest of the world (Grinols (op. cit.)).

We can easily prove the theorem and lemma for coalition $S$ as well by using the same argument. That is, a fictitious market equilibrium allocation for $S$ (keeping $N \backslash S$ fixed) relative to $E(t)$ is in the core for $S$ relative to $E(t)$. This strengthens the Ohyama-Kemp-Wan theorem in the sense that a market equilibrium for $S$ relative to $E(t)$ not only does (weakly) better than the tariff equilibrium allocation in $E(t)$, but also that there is no suballocation attained by subcoalition $S^{\prime} \subset S$ that can do better than the allocation for $S$. An allocation $\left(\left(x_{S}^{i *}, y_{S}^{i *}\right)_{i \in S},\left(x^{i}, y^{i}, p^{i}\right)_{i \in N \backslash S}\right)$ is a core allocation for coalition $S \subseteq$ $N$ relative to $E(t)$, if for any subcoalition $S^{\prime} \subseteq S$, there is no suballocation for $S^{\prime}$ relative to $E(t),\left(\tilde{x}^{i}, \tilde{y}^{i}\right)_{i \in S^{\prime}}$, such that $u^{i}\left(\tilde{x}^{i}\right) \geq u^{i}\left(x^{i *}\right)$ for each $i \in S^{\prime}$. The core for coalition $S \subseteq N$ relative to $E(t)$ is a collection of core allocations for coalition $S \subseteq N$ relative to $E(t)$. The following is a trivial extension of our theorem:

Corollary. The core for coalition $S \subseteq N$ relative to $E(t)$ is nonempty if $x^{i} \in \operatorname{int}\left(X^{i}\right)$ for each $i \in N$. In particular, there exists a market equilibrium 
with Grinols transfers (within $S$ ) and with a common tariff vector that keeps the world price vector intact in the manner of Ohyama-Kemp-Wan, and it is in the core for $S$ relative to $E(t)$.

\section{Conclusion}

Using general equilibrium techniques, we have shown that global free trade with income transfers is in the core when potential customs unions are allowed to have no spillover effects on trade with non-members.

It is interesting to consider why this result has not been established before. One reason is that much research on nations' incentives to block global free trade has focused on economic environments where nations and customs unions are assumed to set optimal tariffs. We have taken the OhyamaKemp-Wan restriction on external tariffs as a given. Another reason is that other research on Ohyama-Kemp-Wan customs unions has focused on the robustness of the Ohyama-Kemp-Wan theorem to changes in tariff-setting rules. We have asked instead whether Ohyama-Kemp-Wan customs unions can block free trade. Finally, much existing research rules out international income transfers. But, as we discuss in Konishi, Kowalczyk, and Sjöström 
(op. cit.), global free trade without income transfers is, in general, not an outcome to which all countries would agree.

We conclude by emphasizing that our result is not a recommendation for revising Article XXIV to require customs unions to have no spillovers or for the implementation of income transfers in multilateral negotiations. We simply note the potential usefulness of restricting the ability of members of customs unions to affect non-members and of international income transfers for free trade in a stylized economic environment.

\section{References}

[1] Bond, E., and C. Syropoulos, 1996, The Size of Trading Blocs: Market Power and World Welfare Effects, Journal of International Economics 40, 411-438.

[2] Debreu, G., 1959, Theory of Value: An Axiomatic Analysis of Economic Equilibrium, New Haven: Yale University Press.

[3] Grandmont, J.-M., and D. McFadden, 1972, A Technical Note on Classical Gains From Trade, Journal of International Economics 2, 109-125. 
[4] Grinols, E. L., 1981, An Extension of the Kemp-Wan Theorem on the Formation of Customs Unions, Journal of International Economics 6, 95-97.

[5] Kemp, M.C., and K. Shimomura, 2001, A Second Elementary Proposition Concerning the Formation of Customs Unions, Japanese Economic Review 52, 64-69.

[6] Kemp, M.C., and H.Y. Wan Jr., 1976, An Elementary Proposition Concerning the Formation of Customs Union, Journal of International Economics 6, 95-97.

[7] Kennan, J, and R. Riezman, 1990, Optimal Tariff Equilibria with Customs Unions, Canadian Journal of Economics 23, 70 - 83.

[8] Konishi, H., C. Kowalczyk, and T. Sjöström, 2003, Free Trade, Customs Unions, and Transfers, The Fletcher School, Tufts University; Social Science Research Network, July 2003; http://ssrn.com/abstract=428346.

[9] Kowalczyk, C., and T. Sjöström, 1994, Bringing GATT into the Core, Economica 61, 301-17. 
[10] Kowalczyk, C., and T. Sjöström, 2000, Trade as Transfers, GATT and the Core, Economics Letters 66, 163-169.

[11] McKenzie, L.W., 1959, On the Existence of General Equilibrium for a Competitive Market, Econometrica 27, 54-71.

[12] Ohyama, M., 1972, Trade and Welfare in General Equilibrium, Keio Economic Studies 9, 37-73.

[13] Riezman, R., 1985, Customs Unions and the Core, Journal of International Economics 19, 355-365.

[14] Viner, J., 1950, The Customs Union Issue, New York: Carnegie Endowment for International Peace. 